\title{
Comparison of Three Different New Bipolar Energy Modalities and Classic Bipolar in Vivo for Tissue Thermal Spread
}

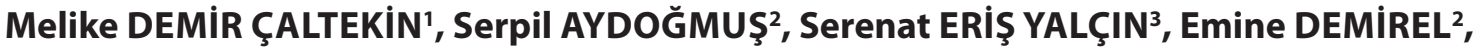 \\ Fulya CAKALAĞAOĞLU UNAY4, Pelin ÖZÜN ÖZBAY5, Aslı Deniz CEYHAN ÖZDEMIR², \\ Yakup YALÇIN ${ }^{6}$, Sefa KELEKÇi ${ }^{2}$
}

\begin{abstract}
Department of Obstetrics and Gynecology, 'Malatya Hospital, MALATYA, TURKEY, ${ }^{2}$ Katip Çelebi University Ataturk Training and Research Hospital, iZMiR, TURKEY, ${ }^{3}$ Isparta Obstetrics and Pediatrics Hospital, ISPARTA, TURKEY, ${ }^{4}$ Department of Pathology, Katip Çelebi University Ataturk Training and Research Hospital, IZMiR, TURKEY, ${ }^{5}$ Department of Obstetrics and Gynecology, Aydin Obstetrics and Pediatrics Hospital, AYDIN, TURKEY,

${ }^{6}$ Department of Gynecologic Oncology, Suleyman Demirel University, Faculty of Medicine, ISPARTA, TURKEY
\end{abstract}

\begin{abstract}
Objective: The aim of this study was to compare three different new bipolar energy modalities and classic bipolar in vivo for tissue thermal spread.

Material and Method: This prospective, randomized, single-blind study was conducted between Septemsber 2012 and July 2013 . Eighteen patients aged 40-65 years undergoing hysterectomy and bilateral salpingectomy for benign etiology were included in the study. Before the hysterectomy operation began, it was marked nearly distal third $\mathrm{cm}$ started from uterine corn and proximal close third $\mathrm{cm}$ started from fimbrial bottoms by visualizing both fallopian tubes. The surgery was performed using one $5 \mathrm{~mm}$ applicator of PlasmaKinetics ${ }^{\mathrm{Tm}}$, EnSeal ${ }^{\circ}$, LigaSure $^{\mathrm{mm}}$ or classic bipolar energy modality. The time each device was used was standardized as the minimum time of the audible warning of the device for tissue impedance and as tissue vaporization on classic bipolar. Tissues were dyed by both H\&E and Masson's Trichrome in the pathology laboratory. Thermal spread was compared.

Results: Evaluation of the damage on the uterine tubes by each device used revealed that LigaSure ${ }^{\mathrm{ma}}$ was associated with increased thermal injury compared to PlasmaKinetics $^{\mathrm{Tu}}(\mathrm{p}=0.007)$. Apart from PlasmaKineticsTM $(\mathrm{p}=0.022)$, there was no statistically significant difference between the three devices in terms of thermal damage spread in the distal and proximal fallopian tubes.
\end{abstract}

Conclusion: To reduce lateral thermal damage, Plasmakinetics ${ }^{\mathrm{Tm}}$ may be preferable to Ligasure ${ }^{\mathrm{Tm}}$ among the three different new bipolar energy modalities.

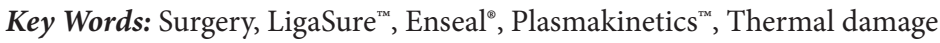

\section{INTRODUCTION}

Energy-based devices are nowadays being used widely in open and laparoscopic surgeries for dissection, cauterization and vessel-sealing purposes. Electrosurgery refers to the use of high frequency electric current for tissue cutting and coagulation processes (1). Since the discovery of electrosurgery in the modern era, various modalities of energy with dissection, cauterization and sealing properties have been produced particularly in laparoscopic surgery. However, despite the advantages of these devices, surgeons are faced with the risk of tissue damage due to peripheral thermal desorption.

Various systems dependent on bipolar energy are being used on tissues and vessels in laparoscopic surgery $(2,3)$. LigaSure $^{\text {tw }}$ fuses collagen and elastin in the vessel wall by

(Turk Patoloji Derg 2017, 33:144-149)

Received : 28.05.2015 Accepted : 26.10.2016 applying a certain amount of bipolar energy and pressure. Heat desorption to adjacent tissues is approximately 2 $\mathrm{mm}(4,5)$. PlasmaKinetics ${ }^{\text {tw }}$ conducts system-pulse bipolar energy to tissues via the device allowing discontinuous tissue cooling which in turn restrains lateral heat desorption and tissue adhesion (6). In the system, high energy is conducted to the grasped tissue creating vapor zones. The current proceeds through highly resistant vapor zones via the least resistant pathway. Vapor zones collapse sequentially and with every new pulse of energy more tissue is coagulated between the tips of the device; consequently, the tissue is coagulated homogenously (7). EnSeal ${ }^{\circ}$ ensures sealing of the tissue by combining energy control of the bipolar sealing device with a compression mechanism. Thermal desorption is approximately $1 \mathrm{~mm}$ (8).

Correspondence: Serenat ERİS YALÇIN

Suleyman Demirel University, Faculty of Medicine

Department of Obstetrics and Gynecology, ISPARTA, TURKEY

E-mail: serenateris@hotmail.com Phone: +90 5350253692 
The widespread use of electrosurgery in time will increase the effectiveness and minimize the risks of the devices. Our study aimed to compare the classic bipolar and three new bipolar energy modalities in terms of lateral thermal propagation in the uterine tubes.

\section{MATERIALS and METHOD}

This prospective, randomized, single-blind study was conducted between September 2012 and July 2013 at the Clinic of Obstetrics and Gynecology of Izmir Katip Çelebi University Ataturk Training and Research Hospital. The study was approved by the Ethics Committee of Izmir Katip Çelebi University and the local academic board (201237). It was consistent with the Declaration of Helsinki for Medical Research Involving human subjects. Informed consent was obtained from all patients.

Eighteen patients aged 40-65 years undergoing hysterectomy and bilateral salpingectomy of benign etiology were included in the study. Patients with previous abdominal surgery, endometriosis, hydrosalpinx or tubal adhesions were excluded. Patients diagnosed with malignancy, endometriosis or hydrosalpinx during frozen sections or postoperative pathologic assessment were also excluded from the study.

Both uterine tubes were visualized and marked proximally $3 \mathrm{~cm}$ from the uterine horn, distally $3 \mathrm{~cm}$ from the fimbrial end before the hysterectomy operation. Energy was applied with $5 \mathrm{~mm}$ wide applicators of each modality. One modality was applied both on the distal and proximal segments of the right uterine tube, and a different modality was applied on the distal and proximal segments of the left uterine tube. Classic bipolar cautery was evaluated as the control group. Application time of each device was standardized as the minimum time needed for an audible warning signal according to the tissue impedance. In the classic bipolar without an audible warning signal, the process was terminated after visualizing tissue vapor. Ultimately uterine tubes were excised by sharp dissection, marked for applicator treated areas and sent to the pathology laboratory (Figure 1). The uterine tubes were fixed in formalin, defined macroscopically and sampled. 3-5 micron thick sections were obtained from paraffin blocks of the uterine tube samples. H\&E and Masson's trichrome (MT) stained sections were evaluated by a single pathologist; areas of damaged or necrotic tissue were morphometrically assessed and compared under light microscopy (Leica DM 4000 B, Leica-Software). The pathologist was blinded to the energy modality used. The incision made by the applicator was considered as the demarcation line; the amount of inflammatory response, tissue congestion, fibrosis and coagulation necrosis formed laterally from this line was recorded and the distance from normal tissue was measured (Figure 2,3).

A total of 72 specimens from 18 patients, applying two different energy modalities on each patient, were evaluated.

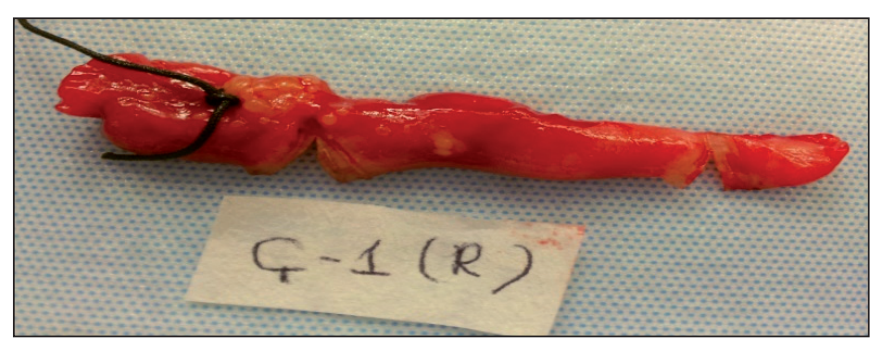

Figure 1: The shape of the uterine tube after energy application.

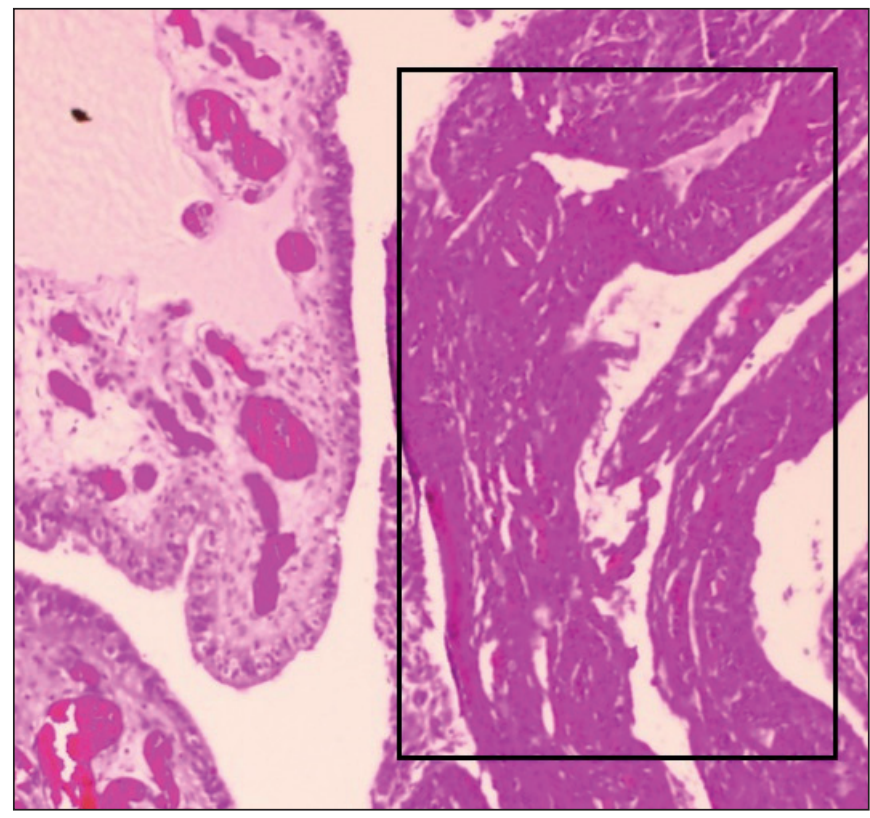

Figure 2: Normal tubal view on the left and coagulation necrosis due to thermal damage on the right (H\&E; x10).

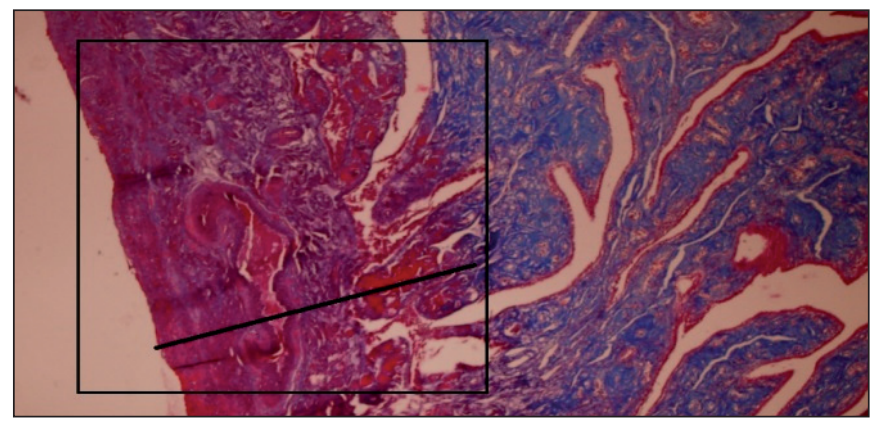

Figure 3: The red coloured area marked with a square indicates thermal damage. The black line is used to measure the propagation of the thermal damage (Masson's Trichrome; $\mathrm{x} 10$ ). 
Each energy modality was compared with other modalities in 3 patients, corresponding to 12 samples (Figure 4).

Data were analyzed by the IBM SPSS 22.0 software (SPSS Inc., IBM, Chicago, IL, USA), and descriptive data were expressed as mean \pm standard deviations (SDs), median and range. The distribution of variables was assessed by the Kolmogorov-Smirnov test. The effect of the device and uterine tubes on thermal damage propagation was evaluated by generalized estimating equations (GEE) model. $\mathrm{p}<0.05$ was considered significant in all analyses.

\section{RESULTS}

The mean age, gravidity and parity of the patients included in the study were $48.4 \pm 5.8,2.8 \pm 1.3$ and $2.1 \pm 1.02$ respectively. 16 patients were in the premenopausal and 2 patients were in the postmenopausal period. Indications and type of the surgery performed are listed in Table I.

Values for spread diffusion of lateral thermal damage on the distal uterine tube tissue in terms of energy modalities applied are $2128 \pm 1116 \mu \mathrm{m}, 1671 \pm 435 \mu \mathrm{m}, 1721 \pm 945$ $\mu \mathrm{m}, 1310 \pm 445 \mu \mathrm{m}$ for LigaSure ${ }^{\mathrm{mm}}$, Enseal ${ }^{\circledR}$, classic bipolar, and Plasmakinetics ${ }^{\text {tix }}$ respectively. Values for propagation of lateral thermal damage on the proximal uterine tube tissue in terms of energy modalities applied are $2294 \pm 693$ $\mu \mathrm{m}, 1860 \pm 858 \mu \mathrm{m}, 1934 \pm 604 \mu \mathrm{m}, 1898 \pm 474 \mu \mathrm{m}$ for LigaSure $^{\mathrm{mw}}$, Enseal ${ }^{\circ}$, classic bipolar, and Plasmakinetics ${ }^{\mathrm{Tm}}$ respectively (Table II).

When the thermal damage on distal and proximal uterine tubes caused by the devices used was considered, values for propagation of the lateral thermal damage $(\mu \mathrm{m})$ on the distal uterine tube in Plasmakinetics ${ }^{\mathrm{m}}$ applied cases were found to be significantly lower than the values for the proximal uterine tube $(\mathrm{p}<0.05)$ (Table II). Although there was no significant difference between distal and proximal uterine tubes in terms of dissemination of the lateral thermal damage in Ligasure ${ }^{\mathrm{m} w}$, Enseal ${ }^{\circ}$, and classic bipolar applied cases, dissemination of the lateral thermal damage on the distal segments was found to be clinically lower than on the proximal segments.

While analysing the damage on uterine tubes by each devices used, Ligasure ${ }^{\mathrm{Tm}}$ was associated with increased thermal injury compared to Plasmakinetics ${ }^{\mathrm{Tm}}(\mathrm{p}=0.007)$ (Table III). When other pathologic parameters such as congestion, necrosis and fibrosis were analyzed by device, there were no statistically significant differences between the groups ( $p>0.05)$.

\section{DISCUSSION}

In our study, three new bipolar energy modalities and the classic bipolar energy modality have been compared in terms of the risks they pose. Studies on thermal tissue damage related to variable energy modalities have been recently gaining importance in the literature. To our knowledge, there are no reported studies to date comparing four different bipolar energy modalities on the same tissue.

In a study of Carbonell et al. in which thermal damage propagations of PlasmaKinetics ${ }^{\mathrm{mm}}$ and LigaSure ${ }^{\mathrm{Tm}}$ on vessels were investigated, thermal damage on the vessels was found to be equal and the damage in greater vessels was found to be wider (9). Unlike this study, our study demonstrated that Ligasure ${ }^{\mathrm{Tm}}$ was associated with increased thermal injury compared to Plasmakinetics ${ }^{\mathrm{Th}}$.

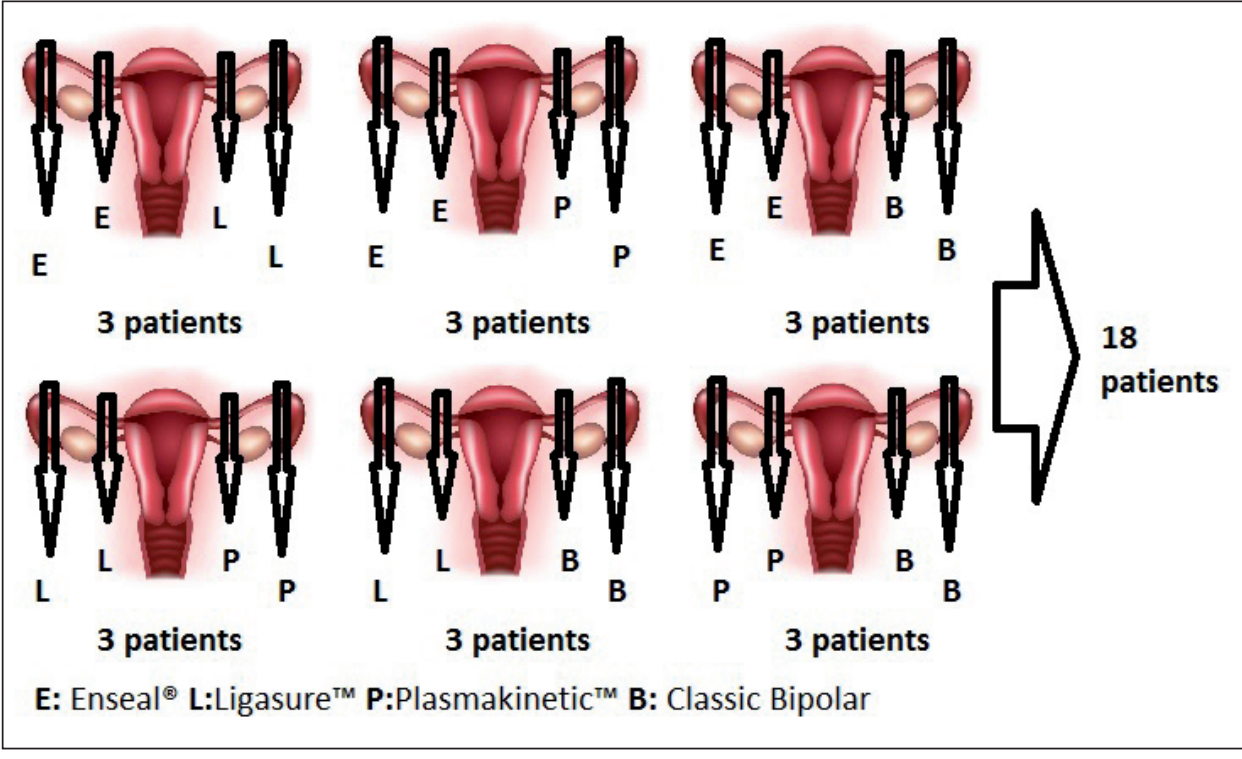

Figure 4: The chart of patient groups according to the use of the devices. 
Table I: Distribution of patient age, gravidity, parity, menopausal status, indications for hysterectomy and the type of surgery performed

\begin{tabular}{lccccc}
\hline & $\mathbf{n}$ & $\%$ & $($ Mean \pm SD) & Min. & Max. \\
\hline Age (years) & & & $48.44 \pm 5.82$ & 40 & 63 \\
\hline Menopausal status & & & & & \\
\hline Postmenopausal & 2 & 11.1 & & & \\
\hline Premenopausal & 16 & 88.9 & & & \\
\hline Gravidity & & & $2.83 \pm 1.34$ & 0 & \\
\hline 0 & 1 & 5.6 & & & \\
\hline 1 & 1 & 5.6 & & \\
\hline 2 & 6 & 33.3 & & \\
\hline 3 & 4 & 22.2 & & \\
\hline 4 & 4 & 22.2 & & \\
\hline 5 & 2 & 11.1 & & \\
\hline Parity & & & $2.11 \pm 1.02$ & & \\
\hline 0 & 1 & 5.6 & & \\
\hline 1 & 2 & 11.1 & & \\
\hline 2 & 11 & 61.1 & & \\
\hline 3 & 3 & 16.7 & & \\
\hline 5 & 1 & 5.6 & &
\end{tabular}

Indications for hysterectomy

Simple Endometrial Hyperplasia without Atypia $\quad 1 \quad 5.6$

Endometrial Polyp $\quad 2 \quad 11.1$

Myoma Uteri $15 \quad 83.3$

\section{Performed Surgery}

$\begin{array}{lcc}\text { TAH+BS* } & 10 & 55.6 \\ \text { TAH+BSO }^{* *} & 5 & 27.8 \\ \text { TAH+Right USO+Left Salpingectomy }^{* * *} & 1 & 5.6 \\ \text { TAH+Left USO+Right Salpingectomy }^{* * * *} & 2 & 11.1\end{array}$

*Total abdominal hysterectomy and bilateral salpingectomy, ${ }^{*}$ Total abdominal hysterectomy and bilateral salpingo-oophorectomy, ${ }^{* * * T o t a l}$ abdominal hysterectomy and right salpingo-oophorectomy and left salpingectomy, ${ }^{* * *}$ Total abdominal hysterectomy and left salpingo-oophorectomy and right salpingectomy.

Table II: Comparison of the results of thermal damage propagation $(\mu \mathrm{m})$ in terms of the devices applied on distal and proximal uterine tubes

\begin{tabular}{lccccccc}
\hline \multicolumn{7}{c}{ Thermal damage propagation $(\mu \mathrm{mm})$} \\
\hline & Dean \pm s.d. & Median & Min-Max. & Mean \pm s.d. & Median & Min-Max. & p \\
\hline Ligasure $^{\mathrm{TM}}$ & $2128 \pm 1116$ & 1745 & $1288-4890$ & $2294 \pm 693$ & 2133 & $1486-3419$ & 1.000 \\
\hline EnSeal $^{\odot}$ & $1671 \pm 435$ & 1614 & $1112-2297$ & $1860 \pm 858$ & 1481 & $877-3369$ & 1.000 \\
\hline Bipolar $^{\text {PlasmaKinetics }}$ & $1721 \pm 945$ & 1486 & $656-3410$ & $1934 \pm 604$ & 1917 & $1005-2723$ & 1.000 \\
\hline
\end{tabular}

Sahin et al. reported that the thermal tissue damage and inflammatory response caused by EnSeal ${ }^{\circ}$ was lower than that of LigaSure ${ }^{\mathrm{rt}}$ in a study comparing the thermal damage and inflammatory responses of EnSeal ${ }^{\circledR}$ and LigaSure ${ }^{\mathrm{T}}$ on the liver (10). Although not statistically significant, thermal damage propagation of EnSeal ${ }^{\oplus}$ in our study was slightly lower than that of LigaSure ${ }^{\mathrm{T} x}$.

In another study, monopolar, harmonic (Pov 3), harmonic (Pov 4) and LigaSure ${ }^{\mathrm{tw}}$ were compared. Thermal damage propagation of LigaSure ${ }^{\mathrm{mm}}$ was measured to be $144.18 \mu \mathrm{m}$ 
Table III: Comparison of the damage on uterine tubes caused by the devices used

\begin{tabular}{|c|c|c|c|c|}
\hline & Mean \pm SD & Median & Min - Max \\
\hline \multicolumn{2}{|l|}{$\mathrm{L}$} & $2211 \pm 905$ & 1982 & $1288-4890$ \\
\hline \multicolumn{2}{|l|}{$\mathrm{E}$} & $1765 \pm 668$ & 1548 & $877-3369$ \\
\hline \multicolumn{2}{|l|}{ B } & $1828 \pm 777$ & 1853 & $656-3410$ \\
\hline \multicolumn{2}{|l|}{$\mathrm{P}$} & $1604 \pm 539$ & 1583 & $804-2713$ \\
\hline \multicolumn{2}{|c|}{ Overall p value } & 0.014 & & \\
\hline \multirow{6}{*}{$\begin{array}{l}\text { Pairwise } \\
\text { comparisons }\end{array}$} & $\mathrm{L}-\mathrm{E}$ & 0.193 & & \\
\hline & L-B & 0.651 & & \\
\hline & L-P & 0.007 & & \\
\hline & E-B & 1.000 & & \\
\hline & E-P & 1.000 & & \\
\hline & B-P & 1.000 & & \\
\hline
\end{tabular}

(11). In Goldstein's study on pig ureters, the approximate thermal damage propagation of LigaSure ${ }^{\mathrm{Tm}}$ was $2110 \mu \mathrm{m}$ (3). Different studies about the same energy modality yielding different results could be explained by variable tissue thicknesses, tissue perfusion and the variability of the energy applied by the device in response to tissue impedance.

Considering the lateral thermal damage propagations of each device on distal and proximal tubal segments in our study, the least-damaging device on the distal uterine tube was PlasmaKinetics $^{\mathrm{mm}}$ whereas the most-damaging device was LigaSure ${ }^{\mathrm{m} w}$. Assessing the lateral thermal damage propagation on the proximal uterine tube, the propagation caused by PlasmaKinetics ${ }^{\text {tw }}$ increased significantly with tissue thickness. This finding could be linked to the variability of tissue impedance related to the difference of muscular intensity in the distal and proximal segments of the uterine tube. However, this trend was not observed in other bipolar energy modalities.

The strength of our study is the comparison of four different devices, all using bipolar energy modalities, on variable thicknesses of the same tissue. To our knowledge, there are no reported studies in the literature comparing these four bipolar energy modalities. Moreover, the comparison of the effects of different energy modalities on the same tissue was enabled by using both tubes of the same person; and the evaluation of the impact of tissue impedance on tissue response created by the energy modalities was enabled by using different thicknesses of the same tube. Propagation of thermal injury could be observed more clearly in our study by using the H\&E and the MT stains. Furthermore, only a few of the studies on this topic have been conducted on living human tissue, the rest being conducted on animals.

A limitation of our study is that the pathology specimens were examined under light microscopy. Pathological alterations in cell damage occur only during the third stage. Therefore, more comprehensive studies are needed to examine the early biochemical and ultrastructural changes thoroughly. In addition, the thermal damage propagation in our study was measured laterally but not vertically; the latter was rendered impossible by the presence of a tissue with a different structure, the peritoneum, under the uterine tube.

Considering the recent advances in surgical energy modalities, nowadays the intention is to increase the effectiveness and minimize the risks of the devices. Herein, we found that Ligasure ${ }^{\text {mot }}$ was associated with increased thermal injury on living human uterine tubes' segments compared to Plasmakinetics $^{\mathrm{mi}}$ and that Plasmakinetics ${ }^{\mathrm{mm}}$ may be preferable to reduce the lateral thermal damage. Energy modalities used on human tissues necessitate clinical studies including larger series.

\section{CONFLICT of INTEREST}

The authors have no conflicts of interest to disclose.

\section{REFERENCES}

1. Massarweh NN, Cosgriff N, Slakey DP. Electrosurgery: History, principles, and current and future uses. J Am Coll Surg. 2006; 202:520-30.

2. Lantis JC II, Durville FM, Connolly R. Comparison of coagulatin modalities in surgery. J Laparoendosc Adv Surg Tech. 1998;8: 381-94.

3. Kim FJ, Chammas MF Jr, Gewehr E, Morihisa M, Caldas F, Hayacibara E, Baptistussi M, Meyer F, Martins AC. Temperature safety profile of laparoscopic devices: Harmonic ACE (ACE), Ligasure V (LV), and plasma trisector (PT). Surg Endosc. 2008;22:1464-9.

4. Goldstein SL, Harold KL, Lentzner A, Matthews BD, Kercher KW, Sing RF, Pratt B, Lipford EH, Heniford BT. Comparison of thermal spread after ureteral ligation with the Laparo-Sonic ultrasonic shears and the Ligasure system. J Laparoendosc Adv Surg Tech A. 2002;12:61-3.

5. Newcomb WL, Hope WW, Schmelzer TM, Heath JJ, Norton HJ, Lincourt AE, Heniford BT, Iannitti DA. Comparison of blood vessel sealing among new electrosurgical and ultrasonic devices. Surg Endosc. 2009;23:90-6.

6. Presthus JB, Brooks PG, Kirchhof N. Vessel sealing using a pulsed bipolar system and open forceps. J Am Assoc Gynecol Laparosc. 2003;10:528-33. 
7. Wang CJ, Yuen LT, Yen CF, Lee CL, Soong YK. Comparison of the efficacy of the pulsed bipolar system and conventional bipolar electrosurgery in laparoscopically assisted vaginal hysterectomy. J Laparoendosc Adv Surg Tech A. 2005;15:361-4.

8. Abstracts of the Global Congress of Minimally Invasive Gynecology, 34th Annual Meeting of the American Association of Gynecologic Laparoscopists, Chicago, Illinois, USA, November 9-12, 2005. J Minim Invasive Gynecol. 2005;12:S1-124.

9. Carbonell AM, Joels CS, Kercher KW, Matthews BD, Sing RF, Heniford BT. A comparison of laparoscopic bipolar vessel sealing devices in the hemostasis of small-, medium-, and large-sized arteries. J Laparoendosc Adv Surg Tech A. 2003;13:377-80.
10. Sahin DA, Kusaslan R, Sahin O, Akbulut G, Bas O, Dilek ON. Histopathological effects of bipolar vessel sealing devices on liver parenchyma and comparison with suture method: an experimental study. Eur Surg Res. 2007;39:111-7.

11. Družijanić N, Pogorelić Z, Perko Z, Mrklić I, Tomić S. Comparison of lateral thermal damage of the human peritoneum using monopolar diathermy, Harmonic scalpel and LigaSure. Can J Surg. 2012;55:317-21. 